\title{
As políticas neoliberais e a crise na América do Sul
}

\section{LUIZ ALBERTO MONIZ BANDEIRA*}

No final dos anos 80, considerada a “década perdida” para o desenvolvimento, a situação não só do Brasil como de toda a América Latina afigurava-se muito difícil e sombria. Solução viável não se percebia para o problema da dívida externa, com o qual os desinvestimentos conjugavam-se, devido à crescente fuga de capitais tanto estrangeiros quanto nacionais, carreando a estagnação econômica, em meio de incontrolável processo inflacionário. Essa crise, que começava a afetar seriamente os interesses dos Estados Unidos ao reduzir na América Latina a capacidade de importar e atender ao serviço da dívida externa, levou o Institute for International Economics ${ }^{1}$ a promover uma conferência, para a qual foram convidados economistas de oito países latino-americanos - Argentina, Brasil, Chile, México, Venezuela, Colômbia, Peru e Bolívia, com a finalidade de formular um diagnóstico e sugerir medidas de ajustamento para sua superação. Naquela oportunidade, o economista norte-americano John Williamson apresentou um documento, que continha dez propostas de reforma econômica, sobre as quais havia amplo consenso em Washington, tanto entre os membros do Congresso e da Administração quanto entre os tecnocratas das instituições financeiras internacionais, agências econômicas do Governo norte-americano, Federal Reserve Board e think tanks ${ }^{2}$. As propostas, visando à estabilização monetária e ao pleno restabelecimento das leis de mercado, consistiam em: 1 - disciplina fiscal; 2 - mudanças das prioridades no gasto público; 3 - reforma tributária; 4 - taxas de juros positivas; 5 - taxas de câmbio de acordo com as lei do mercado; 6 - liberalização do comércio; 7 - fim das restrições aos investimentos estrangeiros; 8 - privatização das empresas estatais; 9 - desregulamentação das atividades econômicas; 10 - garantia dos direitos de propriedade. ${ }^{3}$

A adoção de tais medidas, como a privatização das empresas estatais, a desregulamentação da economia e a liberalização unilateral do comércio exterior pelos países da América Latina constituiria condição fundamental para que pudessem renegociar a dívida externa e receber qualquer recurso das agências financeiras internacionais. Assim eles passariam a depender sempre de financiamentos do BID ou do BIRD para a execução de obras públicas, tendo de 
sujeitar suas respectivas políticas econômicas e decisões de investimentos à fiscalização internacional, por meio de condicionalidades, que ameaçavam atingir igualmente a política de defesa, com a fixação de limites para os gastos militares. Ao mesmo tempo, a liberalização do comércio exterior, promovida unilateralmente pelos países latino-americanos, permitiria que os Estados Unidos, sem mais privilegiar os interesses do setor bancário na questão da dívida externa, atendessem à pressão dos exportadores norte-americanos e transformassem em superávit seu déficit comercial com a região.

O receituário, celebrizado como o Washington Consensus, resumia-se na recomendação de que o Estado se retirasse da economia, quer como empresário quer como regulador das transações domésticas e internacionais, a fim de que toda a América Latina se submetesse às forças do mercado, o que viabilizaria ulteriormente a formação da Área de Livre Comércio das Américas (ALCA), do Canadá à Terra do Fogo, tal como proposta pelo Presidente George Bush, com o lançamento em 1990 de The Enterprise for the Americas Initiative. Esta iniciativa, no contexto das dificuldades para reduzir o desequilíbrio de sua balança comercial por meio da abertura de outros mercados, possibilitaria aos Estados Unidos aumentar ainda mais exportações de mercadorias para os países da América Latina sem a necessidade de negociar com seus governos e fazer outras concessões, dado que com a hegemonia sobre a ALCA obteriam o máximo de liberdade para movimentar bens e fatores de produção (exceto força trabalho), restringindo o acesso ao seu próprio mercado interno, quando lhes conviesse, sob os mais variados pretextos, como competição desleal, riscos sanitários, segurança nacional etc. ${ }^{4}$ Também, mais facilmente eles poderiam enfrentar a União Européia, cujo mercado comum se fechara, bem como o Japão, e também compensar seu déficit comercial com outras regiões. A estabilização monetária e a retomada do crescimento econômico na América Latina tornavam-se sem dúvida necessárias à consecução de tais objetivos.

Essas medidas, consubstanciadas no Washington Consensus, não eram novas. Eram liberais, ortodoxas, similares às que foram tentadas pelos governos militares, sobretudo na Argentina, Uruguai e Chile. Mas, ao fim dos anos 90, a situação na América do Sul afigurava-se ainda mais difícil e sombria do que ao fim da década de 1980. Na Argentina, durante seu primeiro mandato como presidente, Carlos Menem (1989-2000) conseguira controlar a inflação e promover certo crescimento econômico, graças ao câmbio atrelado ao dólar (currency board) e ao ingresso de recursos externos, possibilitado pela privatização das empresas estatais e a brutal desnacionalização da economia. Ao fim do seu governo, porém, a situação financeira da Argentina já se configurava extremamente crítica. Com uma dívida externa da ordem de US\$ 144,6 bilhões, que equivalia a aproximadamente 50\% do seu PIB, estimado em US\$271, 9 bilhões $^{5}$ (1998), ela terminou o ano de 1999 com um déficit na conta corrente do balanço de pagamentos da ordem de US\$12,5 
bilhões e um déficit na balança comercial da ordem de US\$ 2,17 bilhões, enquanto o superávit no comércio intra-regional foi da ordem de US\$2,45 bilhões ${ }^{6}$. O progressivo e rápido agravamento dos "déficits-gêmeos" - o déficit nas contas externas (balança comercial e de serviços) e o déficit nas contas internas do governo - que tinham de ser obrigatoriamente cobertos por importações de capital, começou a gerar desconfiança nos investidores, tanto argentinos como estrangeiros, levandoos a suspender os investimentos diretos, em portfólio ou empréstimos. E, em tais circunstâncias, a expectativa de um default nos pagamentos externos, ou seja, que a Argentina deixasse de cumprir seus compromissos externos (dívida: amortização e/ou juros) - tornou-se real, desde 1998, o que aprofundou a desconfiança e estabeleceu o círculo vicioso da especulação internacional, sobretudo após a crise que atingiu o Brasil no início de 1999. Em 1998, Argentina negociara um acordo com o FMI, de modo que lhe permitisse reduzir o déficit fiscal, mas a prolongada recessão em 1999 impediu o cumprimento da meta estabelecida. Assim, ao suceder a Menem na chefia do governo, Fernando de la Rúa teve de promover aumento de impostos e cortes orçamentários, visando a reduzir o déficit fiscal, que alcançara 2,5\% do PIB em 1999, e recebeu do FMI um empréstimo stand-by da ordem de US\$ 7,4 bilhões para evitar o agravamento da crise. Mas a sobrevalorização do peso, atrelado inflexivelmente ao dólar pela Lei da Conversibilidade, tornara as exportações da Argentina muito caras, dificultando o equilíbrio e, mais ainda, um superávit na balança comercial, apesar de ela ter sido até então o país que mais se beneficiara com a implantação do Mercosul, o único a obter saldo positivo na balança comercial com todos os sócios, desde o estabelecimento da união aduaneira. Entre 1995 e 2000 (nove meses) a Argentina acumulara na sua balança comercial um superávit de US\$ 5,1 bilhões, com o Brasil, de US\$ 1,7 bilhão, com o Paraguai, e de US\$2,2 bilhões, com o Uruguai, totalizando um saldo positivo acumulado de cerca de US\$ 10 bilhões, no período desses cinco anos ${ }^{7}$, enquanto o déficit no intercâmbio com os Estados Unidos totalizou US\$ 16,6 bilhões, maior do que o total do saldo negativo de balança comercial, acumulado no mesmo período, da ordem de US\$ 11,1 bilhões $^{8}$. A crise financeira internacional, que começou na Ásia, em 1997, atingiu a Rússia, em 1998, alcançou o Brasil, em 1999, agravou os problemas estruturais da Argentina, detonando as lutas sociais e acarretando a instabilidade política, com a queda do governo do presidente Fernando de la Rúa, em 22 de dezembro de 2002. À Argentina não restou alternativa senão o default, i. e., a suspensão do pagamento da dívida externa que saltou de US\$ 132 bilhões para US\$ 141 bilhões, no início de 2002.

A situação econômica e financeira, ao fim dos anos 90, configurou-se igualmente crítica no Brasil, apesar de haver construído um dos dez maiores parques industriais do mundo, eficiente na média, e diversificado suas exportações, compostas em mais de 50\% por manufaturas, produtos de tecnologia avançada, que suplantaram o açúcar, café, cacau e outras commodities, com escassa 
elaboração. O governo Fernando Henrique Cardoso, mediante o Plano Real, derrubara a inflação para um único dígito anual, mas não de forma rápida o suficiente para evitar substancial alta da taxa de câmbio real durante sua fase de transição, o que tornou os produtos brasileiros mais caros, em termos internacionais, concorrendo, juntamente com a rebaixa de suas tarifas alfandegárias e as barreiras não-tarifárias mantidas pelos Estados Unidos, para enormes saldos negativos. O Brasil, cujo superávit comercial fora o terceiro maior do mundo nos anos 80 (embora muito abaixo do Japão e da Alemanha), passara a acumular, na balança comercial, saldos negativos que, entre 1996 e 2000, alcançaram o montante de US\$ 38,1 bilhões, ao mesmo tempo em que sua dívida externa aumentou cerca de $100 \%$, saltando de US\$ 123,4 bilhões, em 1990, para US\$ 235 bilhões, em 2000. E esse endividamento conjugado com a perda de competitividade e o desequilíbrio da balança comercial produziram um déficit na conta corrente do balanço de pagamentos que, em 1999, representou cerca $60 \%$ das exportações, abalando a confiança dos investidores, depois da crise na Ásia, em 1997, e da moratória da Rússia, em 1998. O ataque especulativo que, em janeiro de 1999, desvalorizou o real e acarretou a perda de dois terços das reservas internacionais, no transcurso de poucos meses, desgastou profundamente o governo de Fernando Henrique Cardoso, logo no início do seu segundo mandato (1999-2003), conquanto ele houvesse promovido um ajuste econômico, que reduzira o déficit fiscal de mais de 10\% do PIB, em 1999, para 4\% em 2000. Com um PIB, da ordem de US\$ 1 trilhão (calculado pela paridade do poder de compra ${ }^{9}$ ), superior ao do México (US\$ 865,5 bilhões estimado em $1999^{10}$ ) e do Canadá (US\$ 722,3 bilhões), quase duas vezes maior do que o da Rússia (US\$ 620,3 bilhões) e quase tão grande quanto o da França (US\$1,3 trilhão estimado em 1999), Grã-Bretanha (US\$1,3 trilhão estimado em 1999) e Itália (US\$ 1,2 trilhão $)^{11}$, o Brasil continuava, não obstante, como um dos países com maior desigualdade na distribuição de renda, em que a indigência e a pobreza de amplas camadas sociais coexistiam com a ostentação da riqueza e o consumo supérfluo de alguns poucos.

Em 2002, a insolvência que levou a Argentina ao default, configura uma real ameaça para o Brasil, caso o FMI e a comunidade financeira internacional não reduzam para $10 \%$ os juros pagos pelos empréstimos internacionais, atualmente, em torno de $25 \%$. Segundo o que o mega investidor George Soros declarou em palestra na London School of Economics and Political Science (LSE), a moratória do Brasil causaria mais dano a outros países da América do Sul que ficariam fora do mercado de capitais, do que ao próprio Brasil, que tem superávit primário, passou a obter superávit na balança comercial, em 2001, e poderia, por isso, crescer razoavelmente bem depois da reorganização $0^{12}$. Nessa mesma palestra, Soros criticou várias vezes o sistema financeiro internacional, afirmando que, "se um país como o Brasil, que fez todas as coisas certas, está nesta situação, então a globalização falhou”. E, após acentuar que "o Brasil seguiu o consenso de 
Washington, mas isso não significou crescimento”, disse que, quando o sistema não está funcionando bem, é preciso modificá-lo”. A eleição de Luiz Inácio Lula da Silva para a presidência do Brasil indica que o povo deseja essa mudança. E, como também George Soros observou, é "inaceitável” que "a democracia somente é boa, desde que o eleito seja o candidato dos mercados"13.

Todos os demais países na América do Sul igualmente se defrontam, em maior ou menor grau, com uma crise similar. Com uma população de 3,3 milhões, o Uruguai praticamente não se desenvolvera. O PIB, que subira de US\$ 1,9 bilhão, em 1997, para US\$ 2,0 bilhões, em 1998, decaiu para US\$1,9 bilhão, em 1999. O déficit na balança de pagamentos da ordem de US\$ 580 milhões subiu para US\$ 605 milhões. O déficit na balança comercial aumentou de US\$ 1 bilhão, em 1998, para US\$ 1,1 bilhão, em 1999, e US\$1,1 bilhão, em 2000, inferior ao saldo negativo acumulado no intercâmbio com os Estados Unidos, que alcançou US\$ 1,4 bilhão, entre 1995 e $2000^{14}$. No Paraguai, a economia, estagnada desde o término da construção de Itaipu (1982), entrara em franca retração, a partir de 1996, o PIB caiu $0,6 \%$, em 1998 , e $0,1 \%$, em 1999 , e os problemas sociais agravaram-se. O aguçamento da exclusão social, a extrema pobreza, alcançando pelo menos um terço dos camponeses, o aumento do desemprego, saltando de 6\%, em 1995, para 15\%, em 1999, e a deterioração das condições de vida das classes médias tornavam cada vez mais possível uma convulsão social. E, em 5 de junho de 2002, quando cerca de 3.000 camponeses marcharam sobre Assunção, o presidente Luis González Macchi, submetido a processo e diante da ameaça de greve geral por trinta dias, cedeu e derrogou a lei 1.615, que autorizava a privatização da companhia telefônica Copasco, a empresa de água potável Essap e a ferroviária estatal. Oito dias depois, em 14 de junho, a agitação recrudesceu no Peru, onde o povo se levantou contra as privatizações das empresas elétricas Egasa e Egesur, programadas pelo presidente Alejandro Toledo, e o protesto paralisou vários departamentos, sobretudo nas cidades de Arequipa, a segunda do país, e Cusco, estendendo-se até Puno, fronteira com Bolívia, e Tacna, vizinha do Chile.

A situação econômico-social do Chile, apresentado como exemplo do neoliberalismo, que o ditador Augusto Pinochet (1973-1989) implantou, em meio de brutal e sangrenta repressão, não era muito diferente da que se configurava nos demais países da região. Com uma população de 15,3 milhões de habitantes e um PIB da ordem de US\$153,1 bilhões (estimado em 2000 pela paridade do poder de compra) ou US\$ 77,0 bilhões (1999, segundo o método usado na ALADI), sua dívida externa duplicara nos anos 90, saltando de US\$18,5 bilhões (1990) para US\$ 39 bilhões (2000), 9\% de sua força de trabalho estava desempregada (dezembro de 2000), quase um milhão de pessoas viviam abaixo do nível de pobreza e cerca de 700.000 famílias estavam endividadas, como quase toda a classe média ${ }^{15}$. Também na Bolívia, conquanto sua economia crescesse a uma taxa média de 3,9\%, entre 1990 e 1998, e a inflação de 7.000\%, em 1985, para 3\%, em 1999, 
conforme o próprio presidente Hugo Banzer deplorou, a estabilidade econômica ao longo de quinze anos não contribuiu para diminuir os índices de pobreza em que mais da metade da população boliviana (63\%), especialmente a de origem indígena, vivia no ano 2000. A deterioração das condições de vida acelerou-se desde 1985 e, durante os quinze anos em que a Bolívia se apresentou como modelo de livre mercado, atingiu principalmente os camponeses e reduziu à miséria mais de $80 \%$ da população na área rural. A questão agrária, que a revolução de 1952 buscara equacionar mediante a repartição dos latifúndios e distribuição de terras para o trabalhadores rurais ${ }^{16}$, tornou-se outra vez grave fator de tensões sociais e os conflitos sociais irromperam. O aumento das tarifas de água na cidade de Cochabamba, em conseqüência de contrato com uma empresa estrangeira, desencadeou em 7 e 8 de abril de 2000 um levante popular, que se estendeu aos cocaleros (produtores de coca), na região de Chapare, e a outros camponeses e trabalhadores em diferentes cidades. A Confederación Sindical Única de Trabajadores Campesinos de Bolivia (CSUTCB) iniciou então o bloqueio das estradas e, ante a ameaça de convulsão social, em que não apenas os camponeses, mas até estudantes e policiais reclamavam melhoria nas condições de vida ${ }^{17}$, o presidente Hugo Banzer decretou o estado de sítio por noventa dias, intensificando a repressão, que resultou na morte de 6 pessoas, em 74 feridos e 92 presos. A agitação prosseguiu por vários dias e, em 20 de abril, Banzer levantou o estado de sítio, após firmar convênios com os camponeses, intermediados pela Igreja Católica, a Defensoría del Pueblo e a Asemblea Permanente de Derechos Humanos de Bolivia, além de prometer a reativação da economia e pedir perdão pelos pobres que um sistema social excludente e discriminatório produzia. As tensões, porém, voltaram a agravar-se meses depois, quando se anunciou a construção de três bases militares na região de Chapare, com o suporte dos Estados Unidos no marco da luta antidrogas, e outras manifestações de protesto eclodiram, acarretando o bloqueio das estradas e violentos choques entre tropas do exército e camponeses, que se opunham à erradicação dos cultivos de coca e à Ley de Aguas por impedir o funcionamento das redes a seu cargo. A renúncia de Banzer configurou-se como a única saída para apaziguar o país ${ }^{18}$.

A situação do Equador, outro laboratório para a experiência das políticas neoliberais, configurou-se ainda mais difícil do que a da Bolívia. Em março de 1999, ao aprofundar-se a crise econômica e social, o presidente Jamil Mahuad excogitou o fechamento do Congresso, como o presidente Alberto Fujimori fizera no Peru, e só não consumou sua intenção, porque o embaixador norte-americano Leslie Alexander o advertiu de que Washington se oporia a qualquer ruptura da ordem democrática ${ }^{19}$. O próprio Bill Clinton exortou-o, em carta, a "maintain Ecuador's unwavering commitment to democracy”, prometendo apoiar o Equador em suas negociações com o FMI. Porém, quatro meses depois, em 5 de julho de 1999, Mahuad decretou o estado de emergência e mobilizou as forças armadas 
para reprimir a agitação social - greves, bloqueio das principais estradas desencadeada pelo aumento de $13 \%$ no preço dos combustíveis. Essa onda de protestos, promovida inicialmente pelos sindicatos de transporte público, avolumouse, com a adesão dos produtores de banana, principal produto de exportação do país, e o fechamento das estradas, acompanhado pela paralisação das emissoras de rádio e televisão, acarretou a paralisação do comércio e da indústria, bem como o desabastecimento das cidades. Ao presidente Jamil Mahuad não restou alternativa senão derrogar o aumento do preço dos combustíveis ${ }^{20}$. Mas a inquietação social não cessou. Cerca de 10.000 indígenas desceram da serra e marcharam sobre a cidade de Quito, reclamando maior assistência à saúde e à educação para as suas comunidades. E os conflitos sociais recrudesceram, na medida em que a economia do Equador, onde também cerca de $70 \%$ da população viviam na pobreza extrema ${ }^{21}$, cada vez mais se deteriorava, havendo seu PIB, da ordem de US\$19,2 bilhões, em 1998, caído cerca de $12 \%$, em 1999, em meio a uma inflação de $60,7 \%$, a mais alta dos anos $90^{22}$. Em 6 de janeiro de 2000, o presidente Jamil Mahuad, que pretendia promover a dolarização da economia, assessorado por economistas argentinos, entre os quais Domingo Cavallo ${ }^{23}$, decretou outra vez o estado de emergência, suspendendo os direitos constitucionais, e mobilizou o exército para controlar a ordem diante de sucessivas manifestações de protesto, em que os sindicatos, os partidos políticos de oposição e a Confederación de Nacionalidades Indígenas del Ecuador (CONAIE), sob a direção de Antônio Vargas, exigiam sua renúncia. Poucos dias depois, em 10 de janeiro, o Banco Central do Equador aprovou o plano de dolarização e, no dia 15, Mahuad apresentou-se ao Congresso, para defender as leis necessárias à sua implementação e vigência. Mas o estado de emergência não pôde impedir que a insurreição dos indígenas (4,2 milhões em uma população de 12 milhões) recrescesse, com a adesão dos sindicatos e partidos políticos, que exigiam a renúncia de Mahuad, dos deputados e dos membros do Poder Judiciário. E, em 21 de janeiro, um grupo de coronéis levantou o Exército, em apoio às comunidades indígenas, e Mahuad, informado de que não tinha mais condições de segurança no Palácio de Carondelet, refugiou-se em uma base militar, após declarar que não renunciaria. Os indígenas e os militares ocuparam os edifícios públicos, a sede dos três poderes em Quito, e Antonio Vargas proclamou a dissolução do Congresso, bem como da Suprema Corte, anunciou a remoção de Mahuad da presidência do Equador e a formação de um parlamento popular. Pouco mais tarde, foi constituída uma Junta de Salvação Nacional, que foi, entretanto, dissolvida, após intensas negociações com a interveniência dos Estados Unidos, permitindo que o Congresso, em 22 de janeiro, se reunisse em Guayaquil e reconhecesse o vice-presidente Gustavo Noboa como sucessor constitucional de Mahuad. Noboa, ao assumir o governo, tratou de promover as privatizações, da eletricidade aos bancos, e, em março de 2000, tornou o dólar a moeda nacional do Equador, convertido 
em "new Panama", país que havia anos adotara o dólar como moeda corrente e era considerado como de facto o $51^{\circ}$ Estado norte-americano ${ }^{24}$.

Contudo, em depoimento perante o Caucus on International Narcotics Control do Senado norte-americano, o general Charles E. Wilhelm, comandanteem-chefe do Southern Command dos Estados Unidos, reconheceu que, no Equador, como em outras nações situadas na sua área de responsabilidade, a América do Sul, "democracy and free market reforms are not delivering tangible results to the people”. Muitas nações estavam pior economicamente do que antes da restauração da democracia, conforme ele afirmou, perguntando: "Can democracy survive without an economic system that produces adequate subsistence and services for the majority of its citizens?”25. De fato, a situação não melhorou no Equador, cujas reservas monetárias continuaram fracas e instáveis, uma vez que as importações cresceram, sem que houvesse correspondente aumento das exportações, e a balança comercial tornou-se negativa, agravando o déficit do balanço de pagamento e levando o país à anarquia monetária, em conseqüência da dura problemática da dolarização, e à desordem orçamentária. A dolarização da economia não resolvera, antes agravara seus problemas ${ }^{26}$. E os indígenas, em fevereiro de 2002, anunciaram que realizariam novas manifestações de massa, em Quito, contra as privatizações promovidas pelo governo de Gustavo Noboa e a fim de protestar contra o não cumprimento do acordo que pôs fim ao levante, no início de $2001^{27}$.

A Venezuela, por sua vez, abismara-se em uma crise econômica, social e política, desde 1989, quando, apenas alguns dias após a ascensão de Carlos Andrés Pérez, da Acción Democrática, à presidência da Venezuela, o povo saiu às ruas para expressar repúdio ao pacote econômico, um duro plano de ajuste, nos moldes exigidos pelo FMI, que ele pretendeu aplicar. A violenta série de distúrbios e saques culminou com quase 300 mortos e o ambiente de descontentamento recresceu de tal modo que levou o tenente-coronel Hugo Chávez, comandando cerca de 300 efetivos, a tentar um golpe de Estado, em 3 de fevereiro de 1992. O golpe fracassou, mas Chávez tornou-se tão popular que se elegeu legal e legitimamente presidente da Venezuela, em 1998, à frente do Movimiento V República (MVR), com a promessa de promover "una revolución pacífica y democrática”. Chávez, porém, não teve condições de conter a crise econômica e social, apesar de a Venezuela ter sido, juntamente com o Equador, um dos dois únicos países da América do Sul a ter, na segunda metade dos anos 90 , saldo positivo na sua balança comercial, devido às exportações de petróleo para os Estados Unidos. A fuga de capitais e os prejuízos, avaliados entre US\$ 15 e US\$ 20 bilhões, causados pelas enchentes e desabamentos que ocorreram em fins de 1999 deterioraram a situação na Venezuela, que se tornou bastante instável, em fins de 2001, e concorreu para desestabilizar o governo. E, dada a sobrevalorização da moeda venezuelana - o bolívar, Hugo Chávez não teve alternativa, senão liberar o câmbio, no início de 2002, abandonando o sistema de bandas, a fim de estancar a sangria nas reservas 
internacionais, que caíram de US\$ 16,1 bilhões de dólares, em janeiro de 2001, para US\$12,2 bilhões, em dezembro, a maior queda em uma década, o que reduziu as reservas do Banco Central em 23,7\%. Cerca de US\$ 700 milhões evadiram-se da Venezuela somente na primeira semana de fevereiro de 2002. A redução das reservas internacionais, acompanhada pela queda dos preços do petróleo, deixoulhe pouco espaço de manobra. E, em meio a sua pior crise política, Hugo Chávez teve de fazer completa revisão no orçamento de US\$ 34,34 bilhões, com a redução de gastos em $7 \%$ e corte de dívidas do governo pela metade, um ajuste econômico tão forte que derrubou abruptamente o valor do bolívar (19\% em relação ao dólar), e transformou o centro de Caracas em um cenário similar ao de Buenos Aires, onde as manifestações de massa (cazerolazos) derrubaram o governo da dupla Fernando de la Rúa-Domingos Cavallo (19 a 21 de dezembro de 2001). De 11 para 12 de abril, após esses acontecimentos, os generais José Vicente Rangel, Ministro da Defesa, Manuel Rosendo, chefe da segurança do Palácio Miraflores, e Lucas Rincón Romero, chefe do Estado Maior do Exército da Venezuela, prenderam Chávez e anunciaram que ele renunciara à presidência da República. Pedro Carmona Estanca, presidente da Fedecámaras, entidade empresarial, assumiu o governo da Venezuela, mas o golpe de estado, encorajado pelos Estados Unidos, fracassou, em virtude da oposição popular e do repúdio dos demais países da América do Sul.

Na Colômbia, mergulhada em uma cruenta guerra civil havia mais de 40 anos, os guerrilheiros das Forças Armadas Revolucionárias Colombianas (FARC) e do Exército do Povo (EP) controlavam, desde 1997 pelo menos, mais de 622 das 1.071 municipalidades, ou seja, quase a metade do território nacional. A escalada de violência no interior, promovida pelos pára-militares, as FARC-EP e o exército, compeliu mais de 700.000 pessoas a abandonar seus lares, nos últimos anos, elevando para mais de 1,5 milhão o total de refugiados, número muito superior ao de albaneses étnicos que fugiram de Kosovo e o terceiro do mundo, depois dos refugiados do Sudão e de Angola. Legiões de camponeses - entre os quais quase um milhão de mulheres e crianças - empobrecidos, formaram cinturões de miséria em torno de Bogotá e outras grandes cidades, ao tempo em que a Colômbia, em 1998, debatiase na pior recessão de sua história, que reduziu seu PIB, da ordem de US\$ 98,0 bilhões, em 1998, para US\$ 94,2, em 1999, e US\$ 84,8 bilhões, em 2001. Sua dívida externa, da ordem de US\$17,8 bilhões, em 1990, saltou para US\$ 38,9 bilhões, no início de 2002, o que representava quase 50\% do seu PIB, mesmo que ele atingisse, no mesmo ano o montante US\$ 89,6 bilhões. "El Estado colombiano está totalmente quebrado, difícilmente tiene con qué pagar los sueldos y el déficit fiscal será el 31 de diciembre del 4,1\% sobre el producto bruto interno. La Argentina tenía menos cuando estalló la gran crisis” - declarou o ministro do Interior, Fernando Londoño, em 9 de outubro de 2002, quando o déficit fiscal já ultrapassava o montante de US\$ 3,2 bilhões ${ }^{28}$. Por sua vez, o Ministro da Fazenda, Roberto Junguito, advertiu 
que, se o governo financia o gasto público com uma emissão milionária por parte do Banco República "la inflación dispararía”, poderia levar a Colômbia a "una argentinización" da situação econômica. E a perspectiva era ainda mais sombria, devido ao fracasso do processo de paz, à crescente intervenção militar dos Estados Unidos e ao fato de que Álvaro Uribe, logo após assumir a presidência, decretara (agosto de 2002) o estado de exceção, a fim de deter a violência, e anunciou um plano para recrutar um milhão de civis como informantes do exército, medidas que podiam implicar ameaça aos direitos humanos, restrição da oposição política e o estabelecimento de um estado totalitário na Colômbia.

Essa crise, que ao fim dos anos 90 avassalava todos os países da América do Sul, não começou, decerto, com a execução do programa neoliberal do Consenso de Washington. Ela pré-existia. Mas as condições econômicas, sociais e políticas, que nos anos 60 e 70 haviam gerado os movimentos de insurgência, agravaram-se, ao fim de uma década de políticas econômicas neoliberais, executadas por governos democraticamente eleitos. A dívida externa continuou como um problema para toda a América Latina. No fim do ano 2001, segundo o informe "América Latina y el Caribe: Cómo Cierra la Economía en 2001”, elaborado pela Secretaria Permanente do Sistema Econômico Latino-americano (SELA), ela alcançara a “alarmante” cifra de US\$ 784 bilhões, ou seja, cerca de US\$ 30 bilhões a mais que em 2000, e sua tendência era crescer, aproximar-se dos US\$ 800 bilhões, dependendo do montante com que encerrasse a dívida da Argentina ${ }^{29}$. Por outro lado, ao longo dos anos 90, quase todos os países da América do Sul (a Argentina, desde 1992, e o Brasil, a partir de 1994) passaram a ter déficit na sua balança comercial $^{30}$, em conseqüência, sobretudo, da desregulamentação da economia e da abertura unilateral dos mercados, intensificada com os acordos resultantes da Rodada Uruguai do GATT, sem que barreiras não-tarifárias (quotas, técnicas, sanitárias etc.) fossem instituídas, dificultando as importações, como faziam os Estados Unidos e outros integrantes da OCDE (Organização para a Cooperação Econômica e o Desenvolvimento). Em tais circunstâncias, tornou-se cada vez mais difícil para os países da América do Sul atender ao serviço da dívida externa, até então feito, em parte, com o saldo positivo da balança comercial, situação agravada também pelas remessas de lucros, royalties e transferências clandestinas, que recresceram, em conseqüência da desnacionalização das empresas, sobretudo estatais, ao passarem para o controle de capitais estrangeiros.

Novembro de 2002

\section{Notas}

1 O Institute for International Economics fora criado em 1981, com recursos do German Marshall Funds e mantido com doações da Ford Foundation, William and Flora Hewlett Foundation e Alfred P. Sloan Foundation. 
Sobre o tema vide WILLIAMSON, John. The Progress of Policy Reform in Latin America, Washington, DC: Institute for International Economics, January, 1990, p. 9-10. Id. Ibid., p. 10-33.

4 PINHEIRO GUIMARÃES, Samuel. Market Access in ALCA, paper apresentado durante a mesa-redonda do Fifth Colloquium of the Project IDB/ECLAC, Support to the Process of Hemispheric Trade Liberalization, realizado em 28/29 de setembro de 1992 pelo Banco Interamericano de Desenvolvimento e pela Comissão Econômica das Nações Unidas para a América Latina e o Caribe (ECLAC). Manuscrito.

5 Dólares de 1995. De acordo com o INDEC, o PIB da Argentina, em 1998, era da ordem de US\$ 298,3 bilhões, calculado a preços de mercado. http://www.indec.mecon.ar/default.htm. Pelo método de purchasing power parity, usado pelo Banco Mundial, era de US\$ 374 bilhões.

6 http://www.aladi.org/inicio.htm.Vide também http://www.indec.mecon.ar/default.htm.

7 Fonte: ALADI - http://www.aladi.org./inicio.htm.

8 Ibid. No mesmo período, a Argentina teve um déficit comercial que alcançou o montante de US\$ 10,6 bilhões com os países do NAFTA, ao qual Domingo Cavallo queria que a Argentina aderisse. http://www.exante.com.ar/privado/actuales/base/c43.xls.

9 Segundo a paridade do poder de compra, o PIB do Brasil ultrapassava US\$ 1 trilhão (estimado em 1999), sendo o da Argentina da ordem de US\$ 377 bilhões, o do Uruguai, de US\$ 28 bilhões, e o do Paraguai, de US\$19,9 bilhões. CIA-World Factbook (http://www.odci.gov/cia/ publications/factbook/index.html). De acordo com o método tradicional, da ALADI, o PIB do Brasil em 1999 era de US\$ 711,1 bilhões, o da Argentina, de US\$272,9 bilhões, o do Uruguai, de US\$ 19,6 bilhões, e o do Paraguai, de US\$ 8,5 bilhões. http://www.aladi.org/inicio.htm. O PIB do México, segundo o método da ALADI, era de US\$446,2 milhões em 1999. http://www.odci.gov/cia/publications/factbook/index.html.

Soros diz que Brasil pode ter de renegociar sua dívida. BBC Brasil. 08 out. 2002, publicado às 17h15 GMT.

Ibid.

http://www.aladi.org/inicio.htm. As cifras correspondentes ao ano 2000 só abrangem nove meses.

VALLENDAR, Benedikt. Argentinien-Krise belastet Chile. Die Welt, 27 ago. 2001.

BANDEIRA, Moniz, 1998, p. 113-115.

Os setores da oposição não esqueceram o saldo do regime autoritário que Banzer instalou na Bolívia em 1973: 1500 presos políticos, 900 exilados e mais de 200 mortos, entre os quais cerca de 100 camponeses massacrados, em 1974, segundo a Assembléia de Direitos Humanos de Bolívia.

Acometido por grave câncer no pulmão, Banzer, em 6 de agosto de 2001, apresentou sua renúncia ao Congresso nacional, em Sucre, a capital constitucional da Bolívia, e o vice-presidente Jorge Quiroga assumiu o governo.

JOHNSON, Tim Clinton. Clinton: Ecuador must maintain democratic rule, The Miami Herald, 18 mar 1999.

Abdala Bucaram, que tinha sua base política em Guayaquil, foi eleito presidente pelo Partido Roldosista Ecuatoriano (PRE), em 1996, prometendo reformas econômicas e sociais para romper o poder da oligarquia. Líder de personalidade populista e excêntrica (vangloriava-se de ser chamado de El Loco pelo povo), provocou, porém, enorme descontentamento e enfrentou uma onda de protestos, depois de seis meses de governo ao anunciar em $1^{\circ}$ de dezembro de 1996 o aumento dos preços da água, gás, luz e telefones. Como conseqüência, o Congresso, em 6 de fevereiro de 1997, aprovou sua destituição por “incapacidade mental”, de acordo com o art. 100 da Constituição do Equador, e o presidente da Câmara, Fabian Alarcón Rivera, assumiu interinamente o governo, o que foi confirmado por um referendum popular em 1997. Bucaram refugiou-se no Panamá. Com a reforma da Consituição, Jamil Mahuad, do partido Democracia 
Popular, e Gustavo Noboa, do Partido Social Cristão foram eleitos pelo Congresso em 1998.

21 U.S. Department of State. Background Notes: Ecuador, June 2000 Released by the Bureau of Western Hemisphere Affairs. April 2001. http://www.state.gov/r/pa/bgn/index.cfm?docid=2906. http://instruct1.cit.cornell.edu/Courses/crp522/ecbo0900.pdf

Depois que saiu do Ministério da Economia da Argentina, em 1996, Domingo Cavallo foi contratado por Abdalá Bucaram, eleito naquele ano presidente do Equador, para que implantasse um sistema de convertibilidade da moeda equatoriana em dólar. Com a queda de Bucaram, Jamil Mahuad tomou a decisão de dolarizar a economia equatoriana, assessorado por um grupo argentino, que incluía a Fundação Mediterrânea (vinculada a Domingo Cavallo) e o economista Guillermo Calvo, nomeado posteriormente diretor do Banco Interamericano de Desenvolvimento.

24 FAIOLA, Anthony. Washington Post Foreign Service. Thursday, January 25, 2001, p. A01.

25 Statement of General Charles E. Wilhelm, commander-in-chief, U.S. Southern Command, Before the Senate Caucus on International Narcotics Control, March 23, 2000.

26 La dolarización no sacó a Ecuador de la crisis - El sistema acumula serios problemas. La Nación, Buenos Aires, 14 abr 2002.

27 El Universal, Caracas, 08 fev. 2002.

28 La Nacion. Exterior. 10 out. 2002, p. 3.

29 Secretaría Permanente del SELA (Sistema Económico Latinoamericano). Informe de Conyuntura América Latina y el Caribe: Cómo Cierra la Economía en 2001.

30 Somente os Estados Unidos acumularam, com quase todos os países da América do Sul, um superávit comercial. Alcançou o total de US\$ 55,0 bilhões, entre 1995 e 2001 (seis meses).

\section{Resumo}

O presente artigo analisa o efeito social, econômico e político da implementação de políticas neoliberais em países da América do Sul (Argentina, Brasil, Uruguai, Paraguai, Chile, Bolívia, Equador, Venezuela e Colômbia). É destacado o papel da execução do programa neoliberal do Consenso de Washington por governos democraticamente eleitos nos anos 90, para o agravamento da crise externa e interna iniciada nas décadas de 60 e 70 e aprofundada nos anos 80 .

\section{Abstract}

The present article analyses the social, economic and political effects of the neo-liberal politics implementation in some South American countries (Argentina, Brazil, Uruguay, Paraguay, Chile, Bolivia, Ecuador, Venezuela and Colombia). The execution of the Washington Consensus' program by democratically elected governments in the 1990's is pointed as aggravating the internal and external crisis that was initiated in the 1960's and 1970's, and deepened in the 1980's.

Palavras-chave: América do Sul; Políticas neoliberais; Consenso de Washington; Crise. Key words: South America; Neo-liberal politics; Washington Consensus; Crisis. 